\title{
ERRATUM
}

\section{Paternal cocaine taking elicits epigenetic remodeling and memory deficits in male progeny}

ME Wimmer, LA Briand, B Fant, LA Guercio, AC Arreola, HD Schmidt, S Sidoli, Y Han, BA Garcia and RC Pierce

Molecular Psychiatry (2017) 22, 1653; doi:10.1038/mp.2017.71; published online 21 March 2017

Correction to: Molecular Psychiatry advance online publication, 21

February 2017; doi:10.1038/mp.2017.8
In Figures 3 and 5, the expansion of TBS was listed incorrectly. The correct expansion is theta-burst stimulation. The publisher regrets the error. 